\title{
Support for Higher Education Students with Autism Spectrum Disorder
}

\author{
Yuko Furuhashi \\ Shizuoka University, Shizuoka, Japan \\ Email: furuhashi.yuko@shizuoka.ac.jp
}

How to cite this paper: Furuhashi, Y. (2021). Support for Higher Education Students with Autism Spectrum Disorder. Psychology, 12, 567-579.

https://doi.org/10.4236/psych.2021.124035

Received: March 5, 2021

Accepted: April 16, 2021

Published: April 19, 2021

Copyright (c) 2021 by author(s) and Scientific Research Publishing Inc. This work is licensed under the Creative Commons Attribution International License (CC BY 4.0).

http://creativecommons.org/licenses/by/4.0/

\begin{abstract}
Young adults with autism spectrum disorder (ASD) are increasingly attending postsecondary education. However, the graduation rate and academic performance of tertiary-level students with ASD are significantly poorer than that of neurotypical students. In addition, postsecondary students with ASD struggle with loneliness, anxiety, high level of stress, depression, and suicidal behaviors. This review focuses on the current psychological support systems for students with ASD enrolled in higher education. A range of interventions are available, many of which are feasible and show high satisfaction rates among students with ASD. This review shows the need for institutions of higher education to provide psychological supports for students with ASD.
\end{abstract}

\section{Keywords}

Autism Spectrum Disorders, University, College, Students, Intervention

\section{Introduction}

Autism spectrum disorder (ASD) is characterized by significant impairment in social interaction, verbal and nonverbal communication deficits, and restricted and repetitive interests and behavior (APA, 2013). These symptoms range in severity from mild to severe and usually persist throughout the lifespan. While many individuals with ASD have intact or high intellectual ability, non-social neurocognitive impairment has been observed in domains such as aspects of working memory (Williams, 2006), planning (Hughes et al., 1994), and executive functioning (Ozonoff et al., 1994). This constellation of social and non-social deficits in information processing limits adaptation and success in adult life significantly, despite normal intellectual ability. Furthermore, people with ASD are vulnerable to numerous psychiatric and neurological disorders such as depression, epilepsy, sleep disorder, anxiety disorder, and obsessive-compulsive dis- 
order. In addition, hyper- or hyposensitivity to pain, touch, movement, sound, smell, and light have often been reported in this population (Minshew \& Hobson, 2008). Therefore, there is a need for the development of effective intervention in this population (Accardo et al., 2019; Anderson et al., 2018; Van Hees et al., 2015).

As high school graduates with ASD are increasing, colleges and universities around the world are going to meet the needs of a rising number of students with ASD pursuing postsecondary education (Kuder \& Accardo, 2018). Young adults with ASD increasingly identify university graduation as a goal but graduate from university at lower rates than their neurotypical peers (Van Hees et al., 2015). Support throughout postsecondary education is crucial to improving employment outcomes, achieving financial independence, participating in the community, and gaining social acceptance. Moreover, these students will likely need additional instruction in developmentally appropriate social discourse, such as how to negotiate peer and teacher interactions in the classroom, as well as how to access extracurricular activities. When students with ASD transition into college, they face a new set of social demands in an unfamiliar environment that necessitate the use of flexible problem-solving skills (Ashbaugh et al., 2017; Pugliese \& White, 2014). There is substantial need for psychosocial support for postsecondary students with ASD because they feel high levels of anxiety, loneliness, depression, and peer rejection (Gelbar et al., 2015; Mcleod et al., 2019; Van Hees et al., 2015). Loneliness has particularly been associated with depression and anxiety among students with ASD, and may be prevalent among postsecondary students with the disorder, who also struggle with suicidal behaviors (Jackson et al., 2018; Anderson et al., 2020). Their feelings of isolation and loneliness can increase when they avoid certain areas on campus due to sensory sensitivities to noise and crowds (Jackson et al., 2018). While postsecondary educational institutions increasingly offer a range of academic and nonacademic supports for the needs of students with ASD (Anderson et al., 2020), empirical research on their effectiveness is limited (Anderson et al., 2018; Ashbaugh et al., 2017). Students with ASD may experience delays in receiving support because of limited resources, allowing potentially avoidable problems to develop (Anderson et al., 2018; Anderson et al., 2017). Thus, there is a need for further investigation on the availability and accessibility of support systems to address the moods and anxieties in postsecondary students with ASD (Gelbar et al., 2014; Anderson et al., 2020).

The purpose of this article is to identify and analyze the studies that documented firsthand interventions in supporting tertiary education students with ASD.

\section{Methods}

\section{Selection Criteria}

This article includes the studies meeting the following inclusion criteria: 1) study subjects involving individuals with ASD attending a degree-granting college or university; 2) firsthand descriptions of training, support, or interventions of more 
than two individuals; and 3) published in English in a peer-reviewed journal.

An electronic search of the PubMed and Google Scholar databases was conducted to identify relevant studies based on key terms present in the title and abstract. Three search sets were used. The first search set was related to autism and used the terms "ASD" or "autism" or "Asperger" or "pervasive development disorder." The second search set was related to higher education and used the terms "postsecondary" or "college" or "university" or "graduate student". The final search set was related to intervention and used the terms "intervention" or "support" or "training" or "service". The three search sets were linked with the instruction "AND".

The search sets included all papers published in English from January 2014 to March 2020 and excluded dissertation abstracts. After the database search, the abstract and titles of identified papers were then screened as to whether: 1) the participants were postsecondary students with ASD;2) the participants were high-functioning ASD; and 3) a specific intervention or program was designed to address the needs of the students with ASD. After the initial screening of titles and abstracts, the abstracts of papers were reviewed to determine if studies were measuring the impact of a specific intervention or support on students with ASD. The reference lists from the included studies were also searched.

\section{Results}

\subsection{Search Results}

The database search identified 466 papers, the abstracts of which were then manually reviewed to ensure that the studies investigated postsecondary students with ASD. Most of the excluded articles studied adolescents or children for intervention. 45 articles remained after titles and abstracts were screened to ensure that the study focused on university or college students with ASD. 24 articles were excluded because participants did not meet the eligibility criteria. One case report was also excluded. After examination of the full articles, 19 articles were judged to meet inclusion criteria (Figure 1).

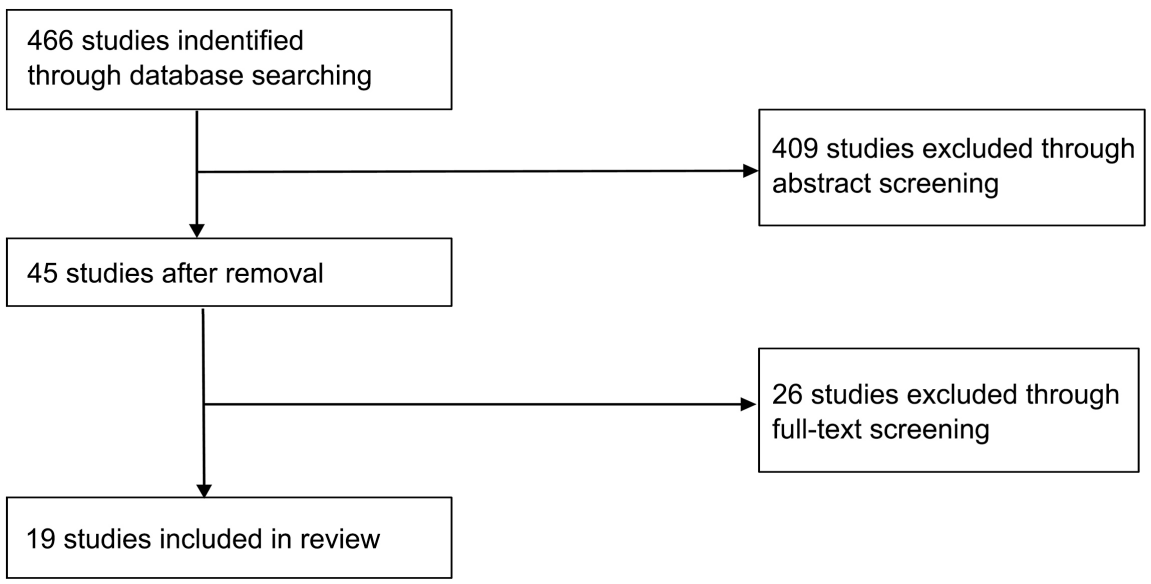

Figure 1. Flow chart for identifying studies. 


\subsection{Overview of the Reviewed Studies}

The 19 articles included in this study were published in peer-reviewed journals and described postsecondary support or interventions in college or university settings. The articles were published after 2013, when the definition of ASD was determined by the APA in the Diagnostic and Statistical Manual for Mental Disorders, Fifth Edition. The sample size in the 19 articles was 3 (Ashbaugh et al., 2017; Jackson et al., 2018) to 52 (Hiller et al., 2018). A total of 297 students with ASD were enrolled in the 19 studies and $81 \%$ of participants were male ( $\mathrm{n}=$ 241). All the papers reported that participants were college or university students with ASD. The interventions were designed to help students develop skills that might enable them to cope with the demands of university life. Most of the interventions showed high effectiveness and rates of satisfaction in participants. The details of these interventions are described subsequently in the paper and Table 1.

\subsection{Details of Each Paper}

Ames et al. (2016) reviewed the ASD Mentorship Program intended to help students with ASD navigate the social and academic framework of postsecondary campus life. Twenty-three students participated. Majority of the students was successful in achieving personal goals and high levels of satisfaction. In addition, the students indicated that they enjoyed the individual meetings with their mentors.

Ashbaugh et al. (2017) demonstrated an intervention that consisted of weekly meetings to plan social activities around the interests of three students with ASD, improve organizational skills, and target specific social skills. In addition, each participant had a peer mentor for support during the social activities. The results showed that, following intervention, all participants demonstrated increased participation in community-based social events, extracurricular activities, and peer interactions, and improved in their Grade Point Average (GPA).

Furuhashi (2017) conducted a group therapy program consisting of CBT and recreational activities to enhance university-related behavior. Fifteen students participated in the program, and 11 students completed it. The results showed significant post-intervention improvements in depressive symptom, anxiety, and self-esteem, which indicated that the group therapy involving CBT was effective for students with ASD.

Hiller et al. (2018) evaluated a support group program for university students with ASD designed to address common challenges including social life on campus, academic skills, managing group work, and time and stress management. They reported that participants showed significantly higher self-esteem, reduced loneliness, and lower anxiety at the end of the program compared to that at the beginning. However, subscales examining social anxiety, academic distress, and depression did not show significant differences.

Jackson et al. (2018) developed the writing learning strategy training on the writing performance of three college students with ASD. One-hour sessions were 
Table 1. Characteristics for literature review studies.

\begin{tabular}{|c|c|c|c|c|}
\hline Author & Publish year & $\begin{array}{l}\text { Participants } \\
\text { (n, M:F, age) }\end{array}$ & Support & Results \\
\hline Ames et al. & 2016 & $\begin{array}{c}23(65 \% \text { male }) \\
18-27 \text { years }\end{array}$ & $\begin{array}{l}\text { peer mentoring, meeting, } \\
\text { workshop }\end{array}$ & $\begin{array}{l}\text { successful, achieving } \\
\text { personal goal }\end{array}$ \\
\hline Ashbbaugh et al. & 2017 & $\begin{array}{c}3(1: 2) \\
\text { mean } 22 \text { years }\end{array}$ & SST with peer mentoring & $\begin{array}{l}\text { increased activities, } \\
\text { GPA improved }\end{array}$ \\
\hline Furuhashi & 2017 & $\begin{array}{c}15(11: 4) \\
\text { mean } 21.0 \text { years }\end{array}$ & group therapy containing CBT & $\begin{array}{c}\text { anxiety and depression } \\
\text { improved }\end{array}$ \\
\hline Hiller et al. & 2018 & $\begin{array}{c}52(51: 1) \\
\text { mean } 20.9 \text { years }\end{array}$ & group therapy containing $\mathrm{CBT}$ & $\begin{array}{l}\text { higher self-esteem, } \\
\text { reduced loneliness }\end{array}$ \\
\hline Jackson et al. & 2018 & $\begin{array}{c}3(2: 1) \\
18-20 \text { years }\end{array}$ & writing learning strategy & $\begin{array}{l}\text { quality of their writing } \\
\text { improved }\end{array}$ \\
\hline Lei et al. & 2020 & $\begin{array}{c}21(11: 10) \\
\text { mean } 18.33 \text { years }\end{array}$ & $\begin{array}{l}\text { social network structure perceived } \\
\text { social support }\end{array}$ & gained friends \\
\hline Longtin & 2014 & $\begin{array}{c}5(4: 1) \\
21-27 \text { years }\end{array}$ & mentor program & academic and social success \\
\hline McCoy et al. & 2014 & $\begin{array}{c}10(10: 0) \\
\text { no data }\end{array}$ & biofeedback & heart rate variability improved \\
\hline $\begin{array}{l}\text { Pearlman-Avnion } \\
\text { and Aloni }\end{array}$ & 2016 & $\begin{array}{c}19(15: 4) \\
23-28 \text { years }\end{array}$ & $\begin{array}{l}\text { peer mentor, residential transition } \\
\text { program, workshops }\end{array}$ & self-efficacy improved \\
\hline Pugliese and White & 2014 & $\begin{array}{c}5(5: 0) \\
\text { mean } 21.3 \text { years }\end{array}$ & $\begin{array}{l}\text { group-based CBT, } \\
\text { problem-solving skills }\end{array}$ & problem-solving skill improved \\
\hline Quinn et al. & 2014 & $\begin{array}{c}29(27: 2) \\
\text { mean } 20 \text { years }\end{array}$ & $\begin{array}{l}\text { skill training based on } \\
\text { university life }\end{array}$ & two-third students satisfied \\
\hline Rando et al. & 2016 & $\begin{array}{l}12(80 \% \text { male }) \\
\text { mean } 19 \text { years }\end{array}$ & $\begin{array}{l}\text { transition program, support group, } \\
\text { peer mentor }\end{array}$ & $\begin{array}{l}\text { increased GPA, high level } \\
\text { satisfaction }\end{array}$ \\
\hline $\begin{array}{l}\text { Roberts and } \\
\text { Birmingham }\end{array}$ & 2017 & $\begin{array}{c}9(7: 2) \\
\text { mean } 21 \text { years }\end{array}$ & a mentee-centered approach & no quantitative data \\
\hline Schindler et al. & 2015 & $\begin{array}{c}11(7: 4) \\
18-20 \text { years }\end{array}$ & $\begin{array}{l}\text { transition program, occupational } \\
\text { therapy, mentoring }\end{array}$ & $\begin{array}{l}9 \text { of } 11 \text { participants } \\
\text { positive results }\end{array}$ \\
\hline Shmulsky et al. & 2015 & $\begin{array}{l}30(85 \% \text { male }) \\
\text { age no data }\end{array}$ & $\begin{array}{l}\text { transition program } \\
\text { (include small group) }\end{array}$ & $\begin{array}{l}\text { academic performance } \\
\text { improved }\end{array}$ \\
\hline Siew et al. & 2017 & $\begin{array}{l}10(7: 3) \\
18 \text { years }\end{array}$ & peer mentoring & $\begin{array}{l}\text { general communication } \\
\text { apprehension improved }\end{array}$ \\
\hline Todd et al. & 2019 & $\begin{array}{c}16(13: 3) \\
18-28 \text { years }\end{array}$ & $\begin{array}{l}\text { 10-week peer mentored physical } \\
\text { activity program }\end{array}$ & $\begin{array}{l}\text { health improved, fostered } \\
\text { belongingness }\end{array}$ \\
\hline Weiss and Rohland & 2015 & $\begin{array}{c}23(15: 8) \\
\text { no data }\end{array}$ & $\begin{array}{l}\text { peer coaching, social groups, } \\
\text { counseling }\end{array}$ & $\begin{array}{l}\text { appreciable gain in } \\
\text { executive function }\end{array}$ \\
\hline White et al. & 2016 & $\begin{array}{c}8(5: 3) \\
18-23 \text { years }\end{array}$ & $\begin{array}{l}\text { virtual reality-brain computer } \\
\text { interface, psychosocial intervention }\end{array}$ & feasible, acceptable enjoyable \\
\hline
\end{tabular}

SST: social skill training CBT: cognitive behavioral training. 
held individually with each student approximately two times per week to deliver the intervention. The learning strategy was referred to as DATE; Developing the thesis statement, adding supporting details, tying it together, and Editing and revising. Ten scripted lessons were used during the intervention, and a multiple baseline across participants design was used to assess the effects of the learning strategy intervention. All three students improved in the quality of their writing.

Lei et al. (2020) evaluated changes in social network structure and perceived social support among first-year students with the ASD $(\mathrm{n}=21)$ and typically developed $(\mathrm{n}=182)$ the first-year students in their transition to the university. Both groups gained friends who provided better support during the first year of university over time. Social anxiety showed a long-term differential negative impact on both the groups.

Longtin (2014) examined the results of Interdisciplinary Collaborative Support Service Program on five students with ASD. Each participating student was each assigned to a graduate student mentor who met with their mentee individually on a weekly basis to provide guidance on college life, social pragmatics, executive function, study habits, relationship building, job search, and self-advocacy. All the mentors agreed that the collaborative support services promoted the academic and social success of their mentees.

McCoy et al. (2014) explored a biofeedback intervention in 10 students with ASD and 37 typical college students. Exploratory data analysis was used to identify trends resulting from a 10-week study. They concluded that both the ASD and the typical groups showed a small improvement in heart rate variability. However, the ASD group demonstrated greater improvement than the typical group.

Pearlman-Avion and Aloni (2016) described an intervention program on the self-efficacy and future orientation of students with high-functioning ASD to accommodate each student according to their individual needs. Nineteen students, aged 23 to 28 , participated in the program. The students who participated in the program shared university-provided housing (dormitories) with their mentors. Students and mentors participated in social and skill-building activities together. In addition, workshops were held throughout the year to enhance the students' life skills, including relationship building, personal communication, and daily living skills. The participants completed the Self Efficacy-Assessment Questionnaire and the Future-Orientation Questionnaire before and after the intervention. The results indicated clear improvement in both measures.

Pugliese and White (2014) implemented a type of group-based cognitive behavioral intervention. They developed a group-based problem-solving therapy to teach problem-solving skills to five college students with ASD. The course began with a psychoeducational component that focused on the relationship between ASD and problem-solving. Through the sessions, students were taught how to identify problems, how to challenge dysfunctional attitudes toward problem-solving, how to regulate negative emotion, how to use their emotions to facilitate problem-solving 
effectiveness, how to practice discrete skills of the problem-solving process, such as problem definition, and how to gather information using brainstorming techniques to generate alternative solutions. The efficacy of the program was evaluated using the Social Problem-Solving Inventory-Revised: Long Form and the Outcome Questionnaire 45.2. Two of the five students showed significant improvements in problem-solving.

Quinn et al. (2014) reported the Unilink Service which aimed to enable the students to develop practical skills and strategies in managing both the academic and social aspects of being university. Unilink was staffed by qualified occupational therapists and was based on the university campus. Twenty-two students with ASD participated in this study from 2006 to 2010. During that period, 50\% - $66 \%$ of students who used the service passed each year. Two-thirds of the students stated that the service was very flexible and available.

Rando et al. (2016) evaluated the Raiders on the Autism Spectrum Excelling (RASE) transition program. The RASE was based on a transition approach that offered more intensive support in the first year. The program provides structure and guidance to students via a transition coach (peer) model that aligns students of similar age and status in college. The RASE incorporates five key competency areas of resiliency, time management and organization, social skill development, technology use, and advocacy. First-year results showed an increase in student GPA, a decrease in behavioral violations, and high levels of satisfaction.

Roberts and Birmingham (2017) described the Autism Mentorship Initiative (AMI), which was modeled off a variety of existing mentorship schemes and involved matching a student with ASD with a neurotypical peer mentor over the course of two semesters. Nine students with high-functioning ASD participated in the AMI. Data were analyzed via a grounded theory approach. Five interrelated main themes emerged, but no quantitative data were reported. In addition, about half of the mentees had difficulty with expressing their ideas despite much effort and variation in techniques provided for the interview structure.

Schindler et al. (2015) studied the efficacy of an occupational therapy mentoring program that assisted students with ASD in the transition to college. The program was conducted during the fall and spring semesters, and students elected to attend once or twice per week for two-hour sessions. The program consisted of one on one mentoring, which paired master's level occupational therapy students with students with ASD under the supervision of occupational therapy faculty. Eleven students participated in the program. The statistically significant results of the Canadian Occupational Performance Measure reflected the participants' perceptions of their ability to positively address problems. Nine of 11 participants had positive objective results.

Shmulsky et al. (2015) assessed a transition program that incorporated six components: 1) Contact students and their parents before the beginning of the academic year; 2) Acclimate small groups of students to campus early; 3) Build alliance with parents; 4) Select trained advisors; 5) Predict and meet residential 
needs; and 6) Provide ongoing support during the first year. Thirty students participated in the orientation program and demonstrated improved academic performance.

Siew et al. (2017) evaluated the efficacy of the Curtin Specialist Mentoring program (CSMP), a specialized peer mentoring program for university students with ASD. Ten students participated in the CSMP. Students completed the Adult Manifest Anxiety Scale-College Version, Social Provisions Scale, Situational Communication Apprehension Measure, Self-Perceived Communication Competence Scale, and Personal Report of Communication Apprehension both prior to and five months after commencing enrolment in the CSMP. Students who participated in the CSMP showed significant improvement in social support and general communication apprehension assessment scores.

Todd et al. (2019) examined the effects of a 10-week, peer-mentored physical activity program called IFiT for college students with ASD. They reported that the participating students gained motor competence, improved their health, and felt a sense of belonging. In the program, the participating students spent time with both students with ASD and typically developed peers, which fostered this belongingness.

Weiss and Rohland (2015) discussed a Communication Coaching Program (CCP) which included disability counseling, communication coaching, peer coaching, social groups, and campus resources. The CCP was conducted 2010-2015, with a total of 23 students with ASD participated. The majority of the participants achieved appreciable gains in executive function/planning and improvement of social-communication skills. However, no quantitative data were reported.

White et al. (2016) reported data from a pilot trial of two intervention programs developed for college students with ASD. In this report, college students with ASD were each assigned to either of two new programs which were an intervention based on virtual reality, Brain-Computer Interface for ASD, and a psychosocial intervention, called College and Living Success. Preliminary evidence supports the feasibility and acceptability of both programs. Eight students with ASD participated in this study. Four of the students were assigned to each of the two experimental programs. Results indicated that expanded research on psychosocial and computer-assisted intervention approaches for this population was warranted, given the preliminary data obtained.

\section{Discussion}

In this paper, 19 empirical studies on interventions for postsecondary students with ASD are reported. A diverse range of interventions were evaluated, most of which showed high effectiveness and rates of satisfaction in participants. However, all papers have different intervention methodologies (i.e., randomly controlled trial, pre-experimental designs), durations, and evaluation scales (i.e., social skills, executive function, grade point average), making it difficult to identify 
the most effective one that can be universally implemented. The limited number of studies and paucity of empirical evidence limit the generalizability of the results. In spite of the limitations, several interesting interventions have been noted such as mentoring and group settings. In addition, university students with ASD preferred peer mentoring and support groups for nonacademic support according to recent surveys (Accardo et al., 2019; Anderson et al., 2020).

Papers published on group setting for high-functioning ASD investigated a cohort of patients at the beginning and end of the intervention program (Pugliese \& White, 2014; Hiller et al., 2018; Furuhashi, 2017; Schindler et al., 2015; Weiss \& Rohland, 2015) demonstrated the feasibility and acceptability of group settings. Most participants in those studies reported that they could talk about their symptoms with group members, and no problems in facilitating the groups were reported.

Several studies on mentoring have also reported on other types of support (Ames et al., 2016; Ashbaugh et al., 2017; Pearlman-Avnion \& Aloni, 2016; Rando et al., 2016; Roberts \& Birmingham, 2017; Schindler et al., 2015; Siew et al., 2017; Todd et al., 2019). The participants indicated that they were extremely satisfied with the mentoring programs, citing the following three reasons for their positive response: 1) Mentors and mentees experienced a natural progression in the relationship, in which they became more open and comfortable. They were able to develop enjoyable peer-like interactions within the relationship; 2) Mentors were supportive and flexible in appropriately assisting mentees with their various needs. In addition, being a familiar supportive connection involved the mentor as a guide and a friend to the mentee; and 3) Mentors and mentees were learning together. Mentors learned about how to mentor students with ASD, whereas mentees learned about the university experience and that many of their challenges were common with several students in postsecondary settings (Roberts \& Birmingham, 2017).

An individual with ASD may feel like an outsider in a group of typically developing peers, which creates feelings of isolation in the individual with ASD. The feelings of isolation may develop into anxiety and depression. Treatment delivered in a group context and mentoring may not only ease feelings of isolation but also provide a natural opportunity for growth in positive social interactions. Group settings including mentoring programs enable social interaction and the sharing of experiences with others, thereby reducing social isolation (Ames et al., 2016; Ashbaugh et al., 2017; Furuhashi, 2017; Hillier et al., 2018; Pearlman-Avnion \& Aloni, 2016; Pugliese \& White, 2014; Rando et al., 2016; Roberts \& Birmingham, 2017; Schindler et al., 2015; Siew et al., 2017; Todd et al., 2019). Most participants also indicated that they found meetings to be the most helpful component of therapies. Furthermore, participants with ASD stated that it was helpful to meet other patients with ASD, have people in similar situations to talk to, see that many of the peers share the same problems, and learn how others with ASD solve their problems. The group setting may have helped nor- 
malize their problems. Group settings and mentorship provides the opportunity to feel accepted and understood by mentors or peers struggling with the same disorder and offers the chance to practice problem-solving skills in a relatively naturalistic, safe, and supportive environment. Thus, group settings and mentorship can provide a sense of being normal and being understood and provide a safe space to talk about an isolated experience. In other words, the group setting and mentorship may offer several advantages over individual therapy. The findings in the studies reviewed are promising, especially given the high rates of comorbidity between ASD and anxiety (Attwood, 2005).

Most of the studies are pre-experimental and generally had a small sample size. The limited number of previous studies and paucity of empirical evidence limit the generalizability of the results. Thus, larger-scale experimental research with longer intervention periods and better descriptions of student characteristics is indicated. In addition, students with ASD cannot ask for support according to a report by Anderson et al. (2020). Thus, it is crucial to develop the best methods of delivery. A more rigorous research design using methodologically strict randomized clinical trials that includes comparisons of treatments and independent evaluators will be required to evaluate treatment efficacy.

\section{Conclusion}

There were 19 studies found that demonstrated feasibility and social validity for interventions that included mentoring, CBT, social skill development, and small size group. Especially, small size group settings and peer mentoring are effective and provide the opportunity to feel accepted and understood by mentors or peers struggling with the same disorder and offer the chance to practice problem-solving skills in a relatively naturalistic, safe, and supportive environment. However, comprehensive approaches designed to address the core neurocognitive and socio-cognitive impairments, and sensory sensitivities in young adults with ASD have yet to be developed. Thus, additional research is needed on effective methods of enhancing the college experiences and outcomes of students with ASD. The increase of students with ASD in higher education is no longer a new phenomenon. Many students with ASD have unique characteristics and need effective accommodation and support. Research is just beginning to identify methods that can be used to support post-secondary students with ASD.

\section{Conflicts of Interest}

The author declares no conflicts of interest regarding the publication of this paper.

\section{References}

Accardo, A. L., Bean, K., Cook, B., Gilles, A., Edgington, R., \& Kuder, S. J. (2019). College Access, Success and Equity for Students on Autism Spectrum. Journal of Autism and Developmental Disorders, 49, 4877-4890. https://doi.org/10.1007/s10803-019-04205-8 
Ames, M. E., McMorris, C. A., Alli, L. N., \& Bebko, J. M. (2016). Overview and Evaluation of a Mentorship Program for University Students with ASD. Focus on Autism and Other Developmental Disabilities, 31, 27-36. https://doi.org/10.1177/1088357615583465

Anderson, A., Carter, M., \& Stephenson, J. (2018). Perspective of University Students with Autism Spectrum Disorder. Journal of Autism and Developmental Disorders, 48, 651-665. https://doi.org/10.1007/s10803-017-3257-3

Anderson, A., Carter, M., \& Stephenson, J. (2020). An On-Line Survey of University Students with Autism Spectrum Disorder in Australia and New Zealand: Characteristics, Support Satisfaction, and Advocacy. Journal of Autism and Developmental Disorders, 50, 440-454. https://doi.org/10.1007/s10803-019-04259-8

Anderson, A., Stephenson, J., \& Carter, M. (2017). A Systematic Literature Review of the Experience and Support of Students with Autism Spectrum Disorder in Post-Secondary Education. Research in Autism Spectrum Disorders, 39, 33-53. https://doi.org/10.1016/j.rasd.2017.04.002

APA (American Psychiatric Association) (2013). Diagnostic and Statistical Manual of Mental Disorders (5th ed.). Arlington: American Psychiatric Publishing. https://doi.org/10.1176/appi.books.9780890425596

Ashbaugh, K., Koegel, R, L., \& Koegel, L. K. (2017). Increasing Social Integration for College Students with Autism Spectrum Disorder. Behavioral Development Bulletin, 22, 183-196. https://doi.org/10.1037/bdb0000057

Attwood, T. (2005). Cognitive Behavioral Therapy for Children and Adults with Asperger's Syndrome. Behavior Change, 21, 147-161.

https://doi.org/10.1375/bech.21.3.147.55995

Furuhashi, Y. (2017). Group Therapy for Japanese University Students with Autism Spectrum Disorder. Psychology, 8, 771-780. https://doi.org/10.4236/psych.2017.85049

Gelbar, N. W., Shefcyl, A., \& Reichow, B. (2015). A Comprehensive Survey of Current and Former College Students with Autism Spectrum Disorder. Yale Journal of Biology and Medicine, 88 , 45-68.

Gelbar, N. W., Smith, I., \& Reichow, B. (2014). Systematic Review of Articles Describing Experience and Supports of Individuals with Autism Enrolled in College and University Programs. Journal of Autism and Developmental Disorders, 44, 2593-2601. https://doi.org/10.1007/s10803-014-2135-5

Hillier, A., Goldstein, J., Murphy, D., Trietsch, R., Keeves, J., Mendes, E., \& Queenan, A. (2018). Supporting University Students with Autism Spectrum Disorder. Autism, 22, 20-28. https://doi.org/10.1177/1362361317699584

Hughes, C., Russell, J., \& Robbins, T. W. (1994). Evidence for Executive Dysfunction in Autism. Neuropsychologia, 32, 477-492. https://doi.org/10.1016/0028-3932(94)90092-2

Jackson, L. G., Duffy, M. L., Brady, M., \& McCormick, J. (2018). Effects of Learning Strategy Training on the Writing Performance of College Students with Asperger's Syndrome. Journal of Autism and Developmental Disorders, 48, 708-721. https://doi.org/10.1007/s10803-017-3170-9

Kuder, C. J., \& Accardo, A. (2018). What Works for College Students with Autism Spectrum Disorder. Journal of Autism and Developmental Disorders, 48, 722-731. https://doi.org/10.1007/s10803-017-3434-4

Lei J., Brosnan, M., Ashwin, C., \& Russell A. (2020). Evaluating the Role of Autistic Traits, Social Anxiety, and Social Network Changes during Transition to First Year of University in Typically Developing Students and Students on the Autism Spectrum. 
Journal of Autism and Developmental Disorders, 50, 2832-2851. https://doi.org/10.1007/s10803-020-04391-w

Longtin, S. (2014). Practice Brief. Interdisciplinary Support Services for Students with Autism Spectrum Disorders. Journal of Postsecondary Education and Disability, 27, 333-342.

McCoy, K. M., Westlake, G., Zucker, S. H., \& DiGangi, S. A. (2014). Evaluation of a Biofeedback Intervention in College Students Diagnosed with an Autism Spectrum Disorder. Journal of the Division on Autism and Developmental Disabilities Council for Exceptional Children, 1, 121-135.

McLeod, J. D., Meanwell, E., \& Hawbaker, A. (2019). The Experience of College Students on the Autism Spectrum: A Comparison to Their Neurotypical Peers. Journal of Autism and Developmental Disorders, 49, 2320-2336.

https://doi.org/10.1007/s10803-019-03910-8

Minshew, N. J., \& Hobson, J. A. (2008). Sensory sensitivities and performance on sensory perceptual tasks in high-functioning individuals with autism. Journal of Autism and Developmental Disorders, 38, 1485-1489. https://doi.org/10.1007/s10803-007-0528-4

Oznoff, S., Strayer, D. L., McMahon, W. M., \& Filloux, F. (1994). Executive Function Abilities in Autism and Tourette Syndrome: An Information Processing Approach. Journal of Autism and Developmental Disorders, 38, 1485-1498. https://doi.org/10.1111/j.1469-7610.1994.tb01807.x

Pearlman-Avnion, S., \& Aloni, A. (2016). The Impact of a Post-Secondary Education Program on the Self-Efficacy and Future Orientation of People with High-Functioning Autism. European Scientific Journal, 12, 251-268. https://doi.org/10.19044/esj.2016.v12n10p\%25p

Pugliese, C. E., \& White, S. W. (2014). Brief Report: Problem Solving Therapy in College Students with Autism Spectrum Disorders: Feasibility and Preliminary Efficacy. Journal of Autism and Developmental Disorders, 44, 719-729. https://doi.org/10.1007/s10803-013-1914-8

Quinn, A., Gleeson, C., \& Nolan, N. (2014). An Occupational Therapy Support Service for University Students with Asperger's Syndrome. Occupational Therapy in Mental Health, 30, 109-125. https://doi.org/10.1080/0164212X.2014.910155

Rando, H., Huber, M. J., \& Oswald, G. R. (2016). An Academic Coaching Model Intervention for College Students on the Autism Spectrum. Journal of Postsecondary Education and Disability, 29, 257-262.

Roberts, N., \& Birmingham, E. (2017). Mentoring University Students with ASD: A Mentee-Centered Approach. Journal of Autism and Developmental Disorders, 47, 1038-1050. https://doi.org/10.1007/s10803-016-2997-9

Schindler, V., Cajiga, A., Aaronson, R., \& Salas, L. (2015). The Experience of Transition to College for Students Diagnosed with Asperger's Disorder. The Open Journal of Occupational Therapy, 3. https://doi.org/10.15453/2168-6408.1129

Shmulsky, S., Gobbo, K., \& Donahue, A. (2015). Practice Brief. Groundwork for Success: A College Transition Program for Students with ASD. Journal of Postsecondary Education and Disability, 28, 235-241.

Siew, C. T., Mazzucchelli, T. G., Rooney, R., \& Girdler, S. (2017). A Specialist Peer Mentoring Program for University Students on the Autism Spectrum: A Pilot Study. PLoS ONE, 12, e0180854. https://doi.org/10.1371/journal.pone.0180854

Todd, T, Miodrag, N., Bougher, S. C., \& Zambom, A. Z. (2019). A Peer Mentored Physical Activity Intervention: An Emerging Practice for Autistic College Students. Autism in Adulthood, 1, 232-237. https://doi.org/10.1089/aut.2018.0051 
Van Hees, V., Moyson, T., \& Roeyers, H. (2015). Higher Education Experiences of Students with Autism Spectrum Disorder: Challenges, Benefits and Support Needs. Journal of Autism and Developmental Disorders, 45, 1673-1688.

https://doi.org/10.1007/s10803-014-2324-2

Weiss, A., \& Rohland, P. (2015). Implementing a Communication Coaching Program for Students with ASD Spectrum Disorders in Postsecondary Education. Topics in Language Disorders, 35, 345-361. https://doi.org/10.1097/TLD.0000000000000071

White, S. W., Richey, J. A., Gracanin, D., Coffman, M., \& Elias, R. (2016). Psychosocial and Computer-Assisted Intervention for College Students with Autism Spectrum Disorder: Preliminary Support for Feasibility. Education and Training in Autism and Developmental Disabilities, 51, 307-317.

Williams, J. H., Waiter, G. D., Gilchrist, A., Perrett, D. I., Murray, A. D., \& White, A. (2006). Neural Mechanisms if Imitation and "Mirror Neuron" Functioning in Autistic Spectrum Disorder. Neuropsychologia, 44, 610-621.

https://doi.org/10.1016/j.neuropsychologia.2005.06.010 